\title{
Expandable drug delivery system for gastric retention based on shape memory polymers: development via 4D printing and extrusion
}

Alice Melocchi ${ }^{\mathrm{a}}$, Marco Uboldi ${ }^{\mathrm{a}}$, Nicoletta Inverardi ${ }^{\mathrm{b}}$, Francesco Briatico-Vangosa ${ }^{\mathrm{c}}$, Francesco Baldi $^{\mathrm{b}}$, Stefano Pandini ${ }^{\mathrm{b}}$, Giulia Scalet ${ }^{\mathrm{d}}$, Ferdinando Auricchio ${ }^{\mathrm{d}}$, Matteo Cerea ${ }^{\mathrm{a}}$, Anastasia Foppoli ${ }^{\mathrm{a}}$, Alessandra Maroni ${ }^{\mathrm{a}}$, Lucia Zema*a ${ }^{\text {, Andrea Gazzaniga }}{ }^{\mathrm{a}}$

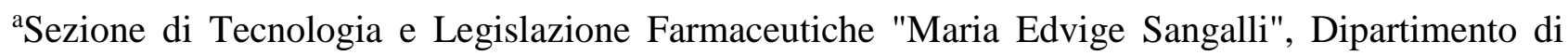
Scienze Farmaceutiche, Università degli Studi di Milano, via G. Colombo 71, 20133 Milano, Italy;

bDipartimento di Ingegneria Meccanica e Industriale, Università degli Studi di Brescia, Via Branze 38, 25123 Brescia, Italy;

'Dipartimento di Chimica, Materiali e Ingegneria Chimica “G. Natta”, Politecnico di Milano, P.zza Leonardo da Vinci 32, 20133 Milano, Italy;

${ }^{\mathrm{d} D i p a r t i m e n t o ~ d i ~ I n g e g n e r i a ~ C i v i l e ~ e d ~ A r c h i t e t t u r a, ~ U n i v e r s i t a ̀ ~ d e g l i ~ S t u d i ~ d i ~ P a v i a, ~ V i a ~ F e r r a t a ~ 3, ~}$ 27100 Pavia, Italy.

*corresponding author: E-mail: lucia.zema@unimi.it; Tel.: 00390250324654. 


\begin{abstract}
Several diseases would benefit from prolonged drug release provided by systems retained in the stomach for extended time periods. Expandable gastroretentive devices are administered in a collapsed configuration enabling swallowing and regain in situ their native shape having larger spatial encumbrance, thus hindering voidance through the wide open pylorus. An expandable system for gastric retention was here proposed relying on the shape memory behavior of pharmaceutical-grade poly(vinyl alcohol). Different original configurations to be recovered upon exposure to aqueous fluids at $37^{\circ} \mathrm{C}$, potentially enabling gastric retention, were conceived. Prototypes containing allopurinol were directly manufactured by fused deposition modeling or shaped by purposely-designed templates from hot melt extruded rods immediately after production. Various temporary shapes, in principle suitable for administration, were programmed by manual deformation of samples by means of specific templates, under defined temperature conditions. In $0.1 \mathrm{~N}$ hydrochloric solution at $37^{\circ} \mathrm{C}$, the prototypes recovered their original shape, reaching the desired spatial encumbrance within few minutes. Release from the samples, although of relatively short duration, was independent of the original shape and processing undergone, and was noticeably slowed down by application of Eudragit RS/RL-based coatings.
\end{abstract}

Keywords: poly(vinyl alcohol); shape memory polymer; hot melt extrusion; fused deposition modeling; 4D printing; gastroretentive drug delivery system. 


\section{Introduction}

Recently, the use of the water-induced shape memory response of swellable soluble polymers was demonstrated to be a viable strategy for the development of an indwelling delivery system for intravesical administration of drugs (Melocchi et al., 2019). The system, based on poly(vinyl alcohol) (PVA) of pharmaceutical grade, was fabricated via hot melt extrusion (HME) and 3D printing by fused deposition modeling (FDM) in a permanent bulky shape enabling retention within the bladder. Its ability to $i$ ) be fixed to a temporary shape suitable for administration, $i i$ ) recover the stress-free permanent shape following interaction with simulated urine at body temperature and iii) dissolve/erode while releasing a drug tracer was demonstrated. Moreover, it was the first 4D printing attempt of a drug delivery system (DDS) using pharmaceutical-grade polymers. A similar approach could be advantageously applied to the development of drug delivery systems to be retained in another hollow organ, such as the stomach, wherein sustained concentrations of drugs are needed in a number of disease conditions.

Gastric retention has long been pursued to enhance the bioavailability of drugs having either an absorption window in the upper gastrointestinal tract (e.g. metformin hydrochloride, baclofen) or lower solubility in the intestinal environment (e.g. captopril, metronidazole, ranitidine hydrochloride), and would also be desirable for the local treatment of gastric or duodenal ulcers, esophagitis and eradication of Helicobacter pylori (Altreuter et al., 2018; Bardonnet et al., 2006; Gupta et al., 2018; Kumar and Kaushik 2018; Lopes et al., 2016) The use of prolonged-release gastroretentive drug delivery systems (GRDDSs) would also increase patient compliance by reducing the dosing frequency. Moreover, it would improve the therapy efficacy by limiting fluctuations in the drug concentration. Therefore, it would be highly advantageous in poor-adherence populations (e.g. children, elderly people and patients with cognitive/mental disorders) and in the therapy of chronic diseases (e.g. diabetes, HIV) that currently require drug administration via injection or other invasive procedures. In the latter case, major benefits would be obtained by prolonging drug release over days/weeks/months. However, gastric retention represents a quite challenging goal due to anatomical, 
mechanical, hydrodynamic and chemical issues involved, such as peristaltic contractions and housekeeper waves, variable fluid volume, propulsive and retropulsive jets of gastric fluid, enzymatic processes, acidic $\mathrm{pH}$. Inter-individual variables, e.g. gender, age, diet, alcohol consumption, physical activity, comorbidities and medications, may also play a critical role.

In order to enable gastric retention, a variety of approaches have been proposed in the scientific literature over the years, basically relying on $i$ ) density modifications, leading to devices undergoing high-density sedimentation or low-density floatation, $\mathrm{ii}$ ) adhesion to the gastric mucosa, $\mathrm{iii}$ ) magnetic localization and/or $i v$ ) size increase preventing passage through the pylorus (Altreuter et al., 2018). Size-increasing GRDDSs, also known as expandable gastroretentive systems, were initially developed for veterinary application and currently represent one of the most promising strategies (Kumar and Kaushik 2018; Lopes et al., 2016; Chen et al., 2000; Klausner et al., 2003a, 2003b; Omidian et al., 2005; Verma et al., 2014). Few of them have already received FDA approval or are in phase III clinical trials (e.g. Depomed's Acuform ${ }^{\circledR}$ technology, IntecPharma's Accordion Pill ${ }^{\mathrm{TM}}$ ) (Altreuter et al., 2018; Klausner et al., 2003b). For safety and efficacy purposes, these systems have to fulfill a number of requirements including $i$ ) convenient and well-tolerated administration mode, ii) prompt achievement of the bulky configuration only upon entry into the gastric environment, iii) retention for a programmed period of time without damaging the stomach walls or interfering with the relevant motility, $i v$ ) mechanical resistance to counteract muscle contraction, $v$ ) controlled release of the drug conveyed irrespective of diverse physiological conditions (e.g. pH fluctuations, presence of food and liquid content), and vi) elimination following reduction in size. In particular, the latter process should take place in such a way as not interfere with physiological stomach emptying and be completed before the administration of a subsequent dose, thus circumventing the risk of accumulation of multiple devices.

Expandable GRDDSs can be distinguished based on the ability to either take on a bulky configuration in the stomach by swelling, or go back to the bulky shape in which they were fabricated. In the latter case, the system is forced after production to a collapsed configuration which enables easy 
swallowing, typically within a carrier dosage form (e.g. a capsule), for instance by folding. Once in the stomach, the system regains its native configuration with larger spatial encumbrance, preventing passage through the wide open pylorus that has diameter ranging between $5.6 \mathrm{~mm}$ and $22.1 \mathrm{~mm}$, more commonly reported to be of $11-13 \mathrm{~mm}$ (Altreuter et al., 2018).

Pioneering research in the field of expandable GRDDSs was recently performed at Massachusetts Institute of Technology (MIT), leading to innovative systems based on either swelling or unfolding (Bellinger et al., 2016; Kirtane et al., 2018; Liu J. et al., 2017; Liu X. et al., 2019). In both cases, great attention was focused on the mechanism of voidance of the devices. Particularly, gastric emptying of the exhausted system was ensured by a decrease in its size, either brought about by exposure to specific substances administered orally when appropriate, or associated with weakening/breaking of purposely designed portions due to diminished resistance to gastric contractions.

Based on these premises, the aim of the present work was to evaluate the feasibility of an expandable GRDDS able to self-modify its configuration upon external stimuli relying on the water-induced shape memory response of pharmaceutical-grade poly(vinyl alcohol) (PVA). The proposed system would thus spontaneously shift from a temporary collapsed configuration, imposed to allow administration, to a bulky original one enabling retention. Unlike previously described expandable GRDDSs based on unfolding, such a shifting would be programmed to occur in a time-dependent mode upon interaction with gastric fluid at body temperature rather than upon removal of a mechanical constraint (e.g. dissolution of the capsule). Therefore, the proposed device would result in a shape-memory expandable GRDDS (SMX GRDDS). Taking advantage of the experience gained in the use of FDM and HME, these techniques were selected for manufacturing of the device in view of the versatility in geometry they are well known to provide, which is of utmost importance due to the critical role played by shape for gastric retention (Beck et al., 2017; Genina et al., 2017; Goyanes et al., 2016; Kollamaram et al., 2018; Loreti et al., 2014; Maroni et al., 2017; Matijašić et al., 2019; Melocchi et al., 2015a, 2015b,2018). Dealing with FDM, because recovery of the original shape of the $3 \mathrm{D}$ printed device is expected to take place over a set period of time, time itself would be 
considered as the fourth dimension, thus resulting in 4D printing (Gao et al., 2016; Lee et al., 2017; Zarek et al., 2015, 2017). This concept refers to production, via different 3D printing techniques, of objects based on smart materials such as shape-memory polymers, intended for self-transformation when exposed to proper external stimuli other than mechanical ones (Ding et al., 2017; Huang et al., 2010; Maniruzzamann, 2018). Interestingly, the approach to gastric retention here pursued has not been used before or reported in the scientific literature, and would also benefit from regulatory acceptability on account of the safety profile of the polymer employed (Melocchi et al., 2018, 2019). Thanks to the solubility of PVA, this system could also be subject to elimination from the stomach because of modification in its steric hindrance and mechanical properties over time, by gradually softening, dissolving and/or eroding when hydrated.

The feasibility of the SMX GRDDS was evaluated by i) designing original shapes in principle enabling gastric retention and setting up appropriate process conditions for manufacturing, ii) identifying temporary shapes compatible with oral administration into capsules and methods for their programming and $\mathrm{iii}$ ) characterizing the obtained prototypes for water-induced shape recovery and release performance. At first, fabrication of systems by FDM was attempted. Subsequently, HME was used, and a systematic work was performed with extruded samples, including study of different shapes, quantitative evaluation of shape recovery and preliminary coating experiments.

\section{Materials and Methods}

\subsection{Materials}

PVA of different molecular weights (PVA05 and PVA18; Gohsenol ${ }^{\mathrm{TM}}$ EG 05P and Gohsenol ${ }^{\mathrm{TM}}$ EG 18P, Nippon Gohsei, J); glycerol (GLY; Pharmagel, I); methacrylic acid copolymer Eudragit ${ }^{\circledR}$ RL100 and Eudragit ${ }^{\circledR}$ RS100 (Evonik, D); triethyl citrate (Sigma Aldrich, D) allopurinol (ALP; FarmaQuimica sur S.L., ES; boiling point $250.36{ }^{\circ} \mathrm{C}$, melting point $>300{ }^{\circ} \mathrm{C}$ ) (https://www.drugbank.ca/drugs/DB00437); carbonium nylon filament $(\varnothing=1.75 \mathrm{~mm}$, 
TreeDFilaments, I); hard-gelatin Coni-snap ${ }^{\circledR}$ capsule size 00el (capacity $1.02 \mathrm{~mL}$, body external diameter $8.18 \pm 0.06 \mathrm{~mm}$, overall closed length $25.3 \mathrm{~mm} \pm 0.03$ ) and DB caps ${ }^{\circledR}$ size AA (capacity $0.80 \mathrm{~mL}$, internal diameter $9.39 \pm 0.06 \mathrm{~mm}$, overall closed length $17.5 \pm 0.03 \mathrm{~mm}$ ) (Capsugel, I).

\subsection{Methods}

\subsubsection{Preparation of PVA-based materials}

Plasticized polymeric formulations containing $15 \%$ by weight of GLY calculated on the dry polymer were prepared starting from PVA05 and PVA18 (PVA05GLY and PVA18GLY). PVA powder, previously kept in an oven at $40{ }^{\circ} \mathrm{C}$ for $24 \mathrm{~h}$, was placed in a mortar and GLY was added dropwise under continuous mixing. The resulting mixture was dried at $40{ }^{\circ} \mathrm{C}$ for $8 \mathrm{~h}$ and possible aggregates were then ground by a blade mill. The $<250 \mu \mathrm{m}$ powder fraction was collected and used. Drugcontaining materials were prepared immediately before processing by mixing in a mortar ALP powder, previously oven-dried at $40{ }^{\circ} \mathrm{C}$ for $24 \mathrm{~h}$, with PVA05GLY or PVA18GLY in a 1:9 weight ratio (PVA05GLY-ALP and PVA18GLY-ALP, respectively).

\subsubsection{Fabrication of SMX GRDDS prototypes}

SMX GRDDS prototypes entailed an original shape resulting from fabrication and a temporary shape attained by programming (Figure 1). Preparation steps were different according to whether FDM or HME was used. 


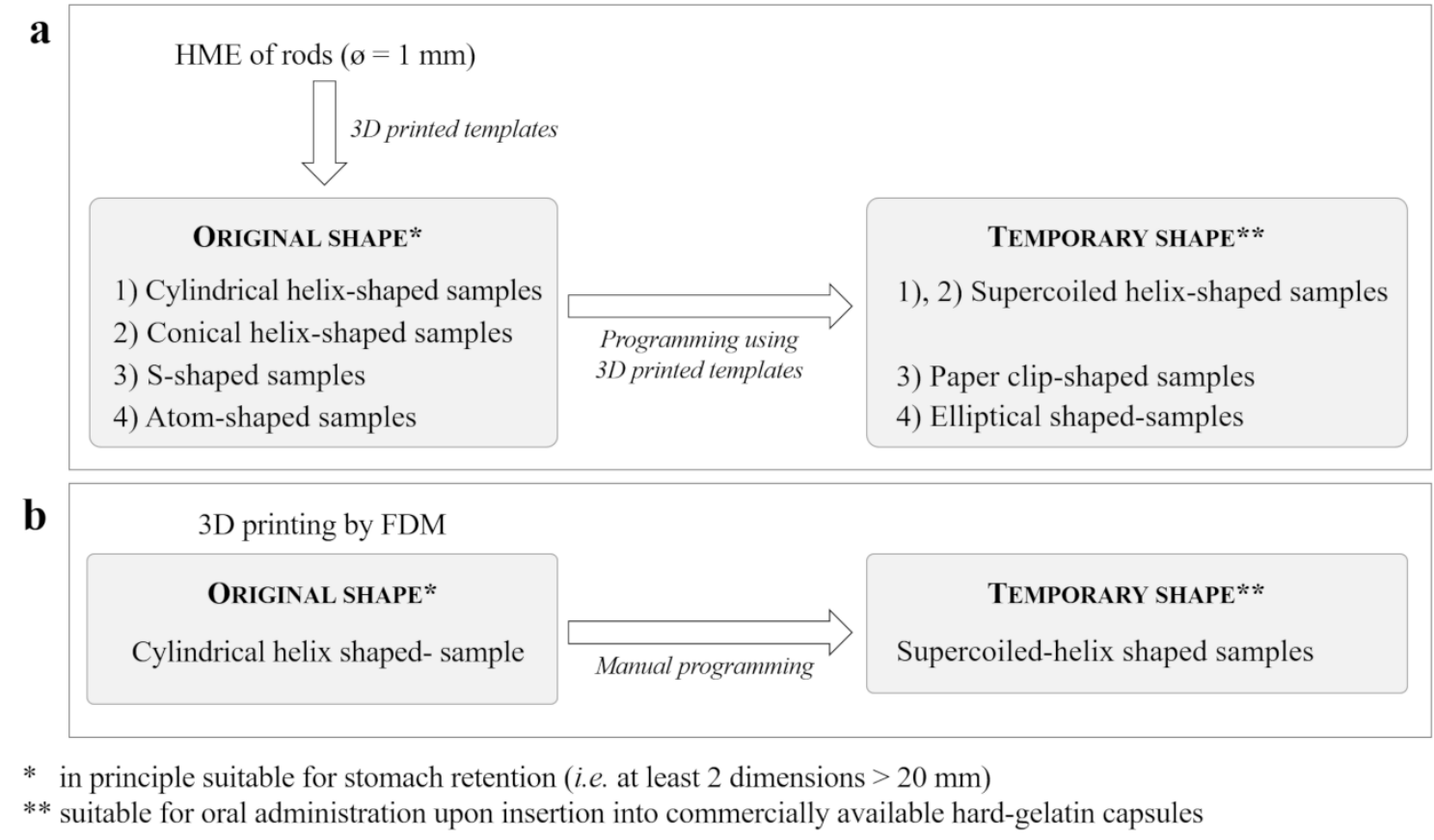

Figure 1: preparation steps of SMX GRDDS prototypes by (a) HME and (b) FDM.

\subsubsection{Hot melt extrusion}

Extrusion was performed by a twin-screw extruder (Haake ${ }^{\mathrm{TM}}$ MiniLab II, Thermo Scientific, US-WI) equipped with counter-rotating screws and different dies under the conditions reported in Table 1.

Table 1: HME process conditions and maximum torque values recorded.

\begin{tabular}{|l|c|c|c|}
\hline \multirow{2}{*}{ Material } & \multicolumn{3}{|c|}{ HME } \\
\cline { 2 - 4 } & $\mathrm{T}\left({ }^{\circ} \mathrm{C}\right)$ & Screw speed $(\mathrm{rpm})$ & Torque $(\mathrm{N} \cdot \mathrm{cm})$ \\
\hline PVA05GLY & 170 & 20 & 100 \\
\hline PVA05GLY-ALP & 175 & 20 & 120 \\
\hline PVA18GLY & 200 & 20 & 190 \\
\hline PVA18GLY-ALP & 200 & 20 & 210 \\
\hline
\end{tabular}

HME was both employed to fabricate filaments for FDM and rods to be shaped into SMX GRDDS prototypes in their original shape.

Filaments were fabricated from PVA05GLY-based materials by extrusion through a custom-made aluminum circular die ( $\varnothing=1.80 \mathrm{~mm}$ ), as previously described (Melocchi et al., 2016, 2019). In order 
to counteract possible swelling phenomena and enhance the yield for filament compliant with the preestablished diameter specifications $(1.75 \pm 0.05 \mathrm{~mm})$, the material coming out of the extruder was manually pulled to pass through a caliper connected with the equipment and set at $1.80 \mathrm{~mm}$. After production and cooling, filament diameter was verified every $5 \mathrm{~cm}$ in length, and portions out of specifications were discarded.

Rods were fabricated from PVA18GLY-based materials by extrusion through a custom-made aluminum circular die $(\varnothing=1.00 \mathrm{~mm})$. While still hot, the rod was wrapped around purposelydeveloped templates, as described in the Results and Discussion section, and removed after 2 min of cooling under pressurized air. Samples having different original shapes, i.e. conical and cylindrical helices, S-shaped and atom-shaped samples, were thereby obtained. The resulting prototypes were packed in heat-sealed alufoil moisture barrier bags before being employed.

Samples of cylindrical helix shape were manually coated up to $60 \%$ weight gain with a $14 \%$ w/w ethanolic solution of Eudragit ${ }^{\circledR}$ RS/Eudragit ${ }^{\circledR} \mathrm{RL}(1 / 1 \mathrm{w} / \mathrm{w})$ plasticized with $15 \% \mathrm{w} / \mathrm{w}$ of triethyl citrate on the dry polymers. Coating was performed at ambient conditions inside an isolated room equipped with an air intake system, a spraying system with a $0.8 \mathrm{~mm}$ nozzle (pump speed $10 \mathrm{rpm}$, atomizer $0.75 \mathrm{~atm}$, pattern $1 \mathrm{~atm})$, and a rotating gear $(2.3 \mathrm{rpm})$ enabling planetary movements. Coated samples were cured in a ventilated oven at $40{ }^{\circ} \mathrm{C}$ for $2 \mathrm{~h}$.

\subsubsection{3D printing}

FDM was performed by a Kloner3D $240^{\circledR}$ Twin (Kloner3D, I) printer equipped with $0.5 \mathrm{~mm}$ nozzle. Computer-aided design (CAD) files were purposely developed as described in the Results and Discussion section using Autodesk ${ }^{\circledR}$ Autocad $^{\circledR} 2016$ software version 14.0 (Autodesk Inc., US-CA) and Netfab (I), specifically employed to increase the mesh number of virtual models. Designs were saved in .stl format and imported to the printer software (Simplify 3D, I). FDM 3D printing was both employed to directly fabricate prototypes of SMX GRDDSs in their original shape and templates. 
Such templates were in turn employed for manual post-processing of extruded rods, to achieve the desired original shape of prototypes, and for programming of their temporary shape.

Prototypes of SMX GRDDSs in their original shape were printed using $25 \mathrm{~cm}$-long portions of the in-house prepared PVA05GLY-ALP filament (printing temperature $=200{ }^{\circ} \mathrm{C}$, infill $=100 \%$, layer height $=0.10 \mathrm{~mm}$, printing speed $=23 \mathrm{~mm} / \mathrm{s}$, separation gap for raft and supports $=0.5 \mathrm{~mm}$ ).

Templates were printed from commercial carbonium nylon filament used as received (printing temperature $=230{ }^{\circ} \mathrm{C}$, infill $=100 \%$, layer height $=0.10 \mathrm{~mm}$, printing speed $=50 \mathrm{~mm} / \mathrm{s}$ ).

\subsubsection{Programming of the temporary shape}

Programming of the temporary shape was performed by heating samples up to the deformation temperature $\approx \mathrm{T}_{\mathrm{g}}+35^{\circ} \mathrm{C}$ (where $\mathrm{T}_{\mathrm{g}}$ is the material glass transition temperature measured by DSC), and manually deforming them with or without using templates, as described in the Results and Discussion section. The temporary shape was then fixed by cooling the deformed samples at $-20{ }^{\circ} \mathrm{C}$ (well below $\mathrm{T}_{\mathrm{g}}$ ). The deformed specimens were maintained under this temperature for at least $1 \mathrm{~h}$ before testing.

\subsubsection{Evaluation of SMX GRDDS prototypes}

\subsubsection{Shape recovery}

Recovery of the original shape was studied upon immersion of the deformed samples into a crystallization vessel, filled with $250 \mathrm{~mL}$ of unstirred $\mathrm{HCl} 0.1 \mathrm{~N}$ and kept at $37 \pm 0.5^{\circ} \mathrm{C}$ by means of a thermoregulated bath. When the samples in their temporary shape were inserted into a capsule, the latter was glued to a microscope slide placed into the crystallization vessel to avoid floating. The recovery process was monitored using digital cameras positioned above (distance $13 \mathrm{~cm}$ ) and in front of (distance $10 \mathrm{~cm}$ ) the specimen (GoPro Hero Session, US-CA; $\mathrm{n}=3$ ). The photographs acquired were processed using a specific software (ImageJ, US-MD). For each shape, recovery indices were calculated and recovery index (RI) versus time curves were built. RI were calculated as follows: 
- for samples having original cylindrical helix shape (Figure 2a), which undergo supercoiling and extension in the programming of the temporary shape

$R I_{\varnothing}(\%)=\frac{\emptyset_{t}-\emptyset_{0}}{\emptyset_{i}-\emptyset_{0}} \times 100$

where RI $\varnothing$ is the diameter recovery index, being $\emptyset_{\mathrm{i}}$ the diameter measured in the original configuration, $\varnothing_{0}$ the diameter measured in the temporary shape and $\varnothing_{\mathrm{t}}$ the diameter measured during shape recovery;

$R I_{\varnothing / h}(\%)=\frac{(\varnothing / h)_{t}-(\varnothing / h)_{0}}{(\varnothing / h)_{i}-(\varnothing / h)_{0}} \times 100$

where $\mathrm{R} \mathrm{I}_{\varnothing / \mathrm{h}}$ is the diameter-to-height ratio recovery index, being $(\varnothing / h)_{i}$ the diameter-to-height ratio measured in the original configuration, $(\varnothing / h)_{0}$ the diameter-to-height ratio measured in the temporary shape and $(\varnothing / h)_{t}$ the diameter-to-height ratio measured during shape recovery;

- for samples having original conical helix shape (Figure 2b), which undergo supercoiling and extension in the programming of the temporary shape

$R I_{\varnothing}(\%)=\frac{\emptyset_{t}-\emptyset_{0}}{\emptyset_{i}-\emptyset_{0}} \times 100$

where RIø is the base diameter recovery index being $\varnothing_{\mathrm{i}}$ the base diameter measured in the original configuration, $\varnothing_{0}$ the base diameter measured in the temporary shape and $\varnothing_{\mathrm{t}}$ the base diameter measured during shape recovery;

$R I_{\varnothing / h}(\%)=\frac{(\varnothing / h)_{t}-(\varnothing / h)_{0}}{(\varnothing / h)_{i}-(\varnothing / h)_{0}} \times 100$

where $\mathrm{RI} \varnothing / \mathrm{h}$ is the base diameter-to-height ratio recovery index, being $(\varnothing / h)_{i}$ the base diameter-toheight ratio measured in the original configuration, $(\varnothing / h)_{0}$ the base diameter-to-height ratio measured in the temporary shape and $(\varnothing / h)_{t}$ the base diameter-to-height ratio measured during shape recovery;

- for samples having original S shape (Figure 2c), which undergo a complex deformation into a paper clip shape during the programming of the temporary shape

$R I_{\alpha_{x y}}(\%)=\frac{\alpha_{x y_{t}}-\alpha_{x y_{0}}}{\alpha_{x y_{i}}-\alpha_{x y_{0}}} \times 100$ 
where $R I_{\alpha_{x y}}$ is the $\alpha_{x y}$ recovery index, being $\alpha_{x y_{i}}$ the angle measured in the original shape, $\alpha_{x y_{0}}$ the angle measured in the temporary shape and $\alpha_{x y_{t}}$ the angle measured during shape recovery;

$R I_{\alpha_{y z}}(\%)=\frac{\alpha_{y z_{t}}-\alpha_{y z_{0}}}{\alpha_{y z_{i}}-\alpha_{y z_{0}}} \times 100$

where $R I_{\alpha_{y z}}$ is the $\alpha_{\mathrm{yz}}$ recovery index, being $\alpha_{z y_{i}}$ the angle measured in the original shape, $\alpha_{y z_{0}}$ the angle measured in the temporary shape and $\alpha_{z y_{t}}$ the angle measured during shape recovery;

$R I_{\alpha_{x z}}(\%)=\frac{\alpha_{x z_{t}}-\alpha_{x z_{0}}}{\alpha_{x z_{i}}-\alpha_{x z_{0}}} \times 100$

where $R I_{\alpha_{x z}}$ is the $\alpha_{x z}$ recovery index, being $\alpha_{x z_{i}}$ the angle measured in the original shape, $\alpha_{x z_{0}}$ the angle measured in the temporary shape and $\alpha_{x_{t}}$ the angle measured during shape recovery.

Since the samples can lie on two different planes in the crystallization vessel once they are no longer inside the capsule, only two angles can be measured at a time during the recovery of the original S shape. Therefore, the experiments for S-shaped samples were replicated twice. In Figure 2c an example is shown where $\alpha_{x y}$ and $\alpha_{x z}$ were measured on the same specimen by the two cameras, and $\alpha_{\mathrm{yz}}$ was evaluated on a different sample. 

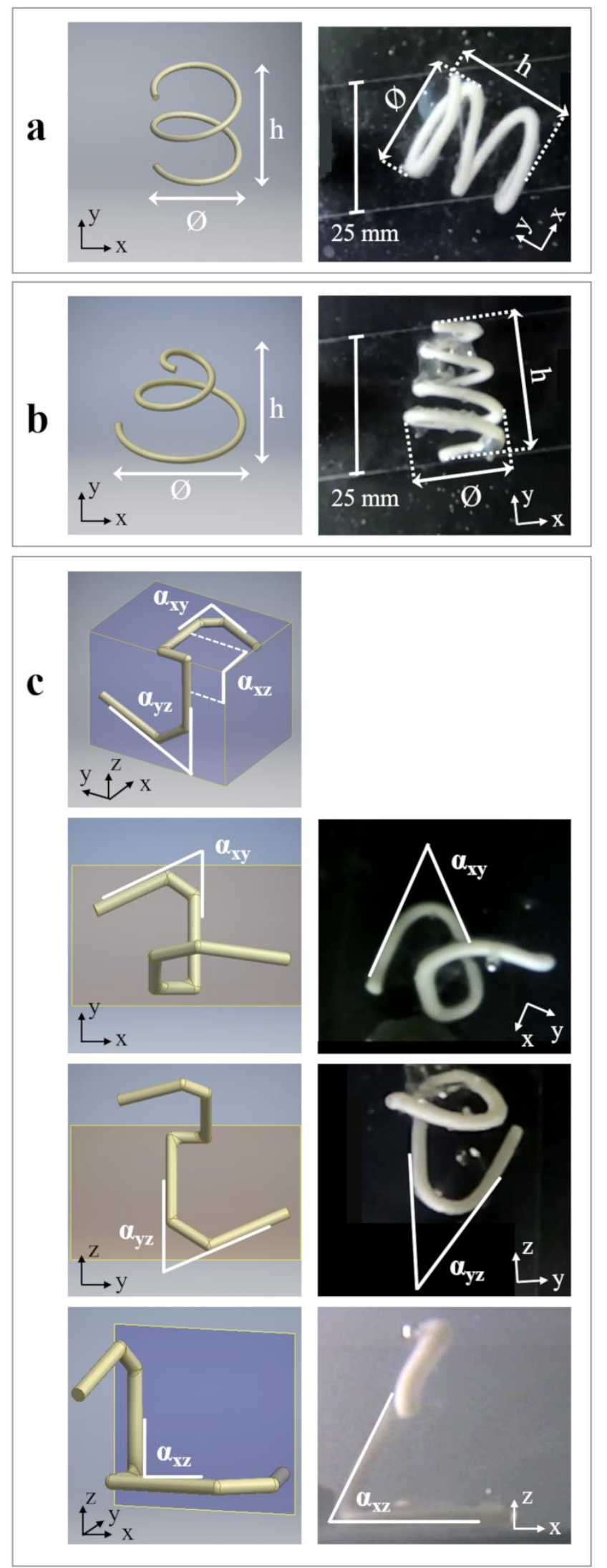

Figure 2: (left) virtual models of (a) cylindrical helix-, (b) conical helix- and (c) S-shaped samples, and (right) photographs of relevant specimens during shape recovery; parameters (i.e. diameter, height and angles) used to calculate RI are indicated. 


\subsubsection{Release performance}

ALP-containing samples, either immediately after fabrication or following deformation into their temporary shape and insertion into a capsule, were tested for release using a USP38 dissolution apparatus $2\left(50 \mathrm{rpm}, 37 \pm 0.5{ }^{\circ} \mathrm{C}, 900 \mathrm{~mL} \mathrm{HCl} 0.1 \mathrm{~N}\right.$; Distek, $\left.\mathrm{CH} ; \mathrm{n}=6\right)$. Fluid samples were withdrawn at specific time points and assayed spectrophotometrically $(\lambda=251 \mathrm{~nm})$. During the release test, photographs of samples were acquired every $5 \mathrm{~s}$ (GoPro Hero Session, US-CA).

\subsubsection{Differential scanning calorimetry (DSC)}

DSC analyses were performed by a DSC Q100 TA Instruments equipment (US-DE; $\mathrm{n}=1$ ), using nitrogen as a purge gas $(70 \mathrm{~mL} / \mathrm{min})$. Indium was used as a calibration standard. Samples of about 10 $\mathrm{mg}$ were heated in aluminum pans from $-50{ }^{\circ} \mathrm{C}$ to $240{ }^{\circ} \mathrm{C}$, maintained at this temperature for 1 min, cooled down to $-50{ }^{\circ} \mathrm{C}$ and reheated up to $240{ }^{\circ} \mathrm{C}$. Both the heating and cooling steps were run at 10 ${ }^{\circ} \mathrm{C} / \mathrm{min}$.

\section{Results and Discussion}

Taking advantage of the experience previously gained in the development of indwelling PVA-based devices for intravesical administration of drugs, the main challenges to be faced were related to the peculiar characteristics of the new site for DDS retention.

\subsection{Drug tracer selection}

ALP, a xanthine oxidase inhibitor used as the first-line therapy for gout and hyperuricemia, was chosen as a model molecule in view of its greater absorption from the stomach, being in its nonionized form in the acidic medium ( $\mathrm{pK}_{\mathrm{a}}$ 9.4), and from the duodenum as well as the upper jejunum (Jaeger et al., 1982; Rouge et al., 1996; Sharma et al., 2015). Indeed, this drug has already been proposed as a candidate for being administered via a GRDDS combining floating and mucoadhesion 
strategies (Sharma et al., 2015). Moreover, its high melting point would make it in principle suitable for processing under the temperature conditions required by the employed manufacturing techniques. PVA-based formulations containing ALP, and GLY as the plasticizer, were subjected to a DSC cycle between $-50{ }^{\circ} \mathrm{C}$ and $240{ }^{\circ} \mathrm{C}$ in order to assess the material $\mathrm{T}_{\mathrm{g}}$. Indeed, the temporary shape of a PVAbased SMX GRDDS has to be programmed by heating samples above $\mathrm{T}_{\mathrm{g}}$, and maintained by keeping them below $\mathrm{T}_{\mathrm{g}}$. Moreover, the recovery of the original shape would occur when the systems are exposed at a temperature above $\mathrm{T}_{\mathrm{g}}$, i.e. the body temperature. In Figure 3 DSC thermograms acquired are reported.

a

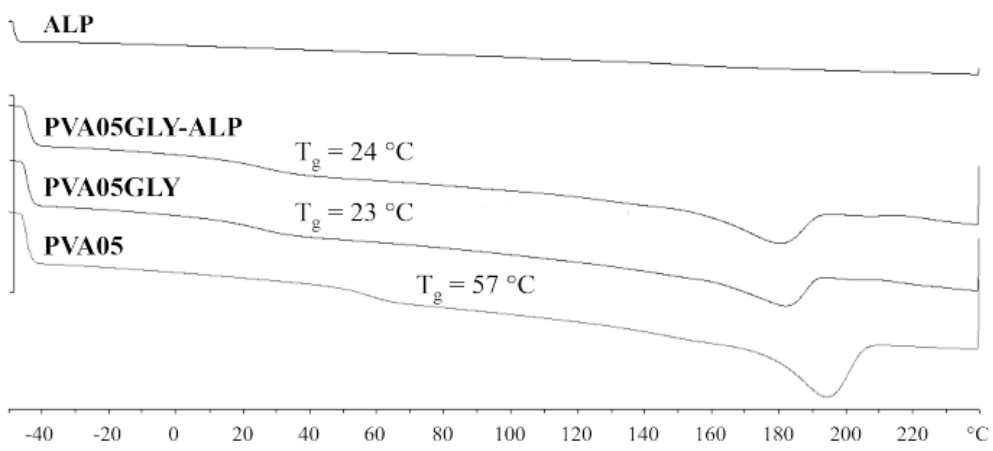

b

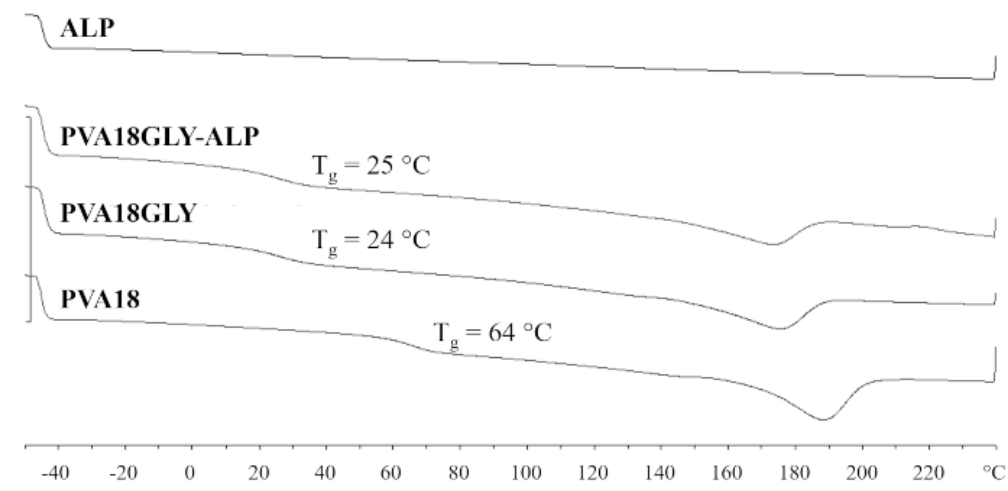

Figure 3: DSC thermograms (a) PVA05- and (b) PVA18-based materials. Thermograms relevant to ALP as such are also reported.

The plasticization effect of GLY on PVA, indicated by a decrease in $T_{g}$, was confirmed (Melocchi et al., 2019; Mohsin et al., 2011). On the contrary, the presence of ALP was demonstrated not to affect the $\mathrm{T}_{\mathrm{g}}$ of PVA05GLY and PVA18GLY. 


\subsection{Design concept}

The original and the temporary shape of the SMX GRDDS under development should be compliant with the route of administration and the characteristics of the retentive organ. Accordingly, the original shape given on fabrication was conceived so as to provide the system with a spatial encumbrance that would prevent stomach emptying, i.e. at least 2 dimensions greater than $13 \mathrm{~mm}$. Moreover, it would have to be endowed with large void volumes not to prevent passage of gastric fluids through the pyloric sphincter, should the device be positioned in its close proximity during residence in the stomach. On the other hand, the temporary shape to be imposed by subsequent deformation should be such as to allow conveyance of the device in a carrier system (e.g. a gelatin capsule) and easy swallowing. The shift from the latter to the former configuration should spontaneously take place after dissolution/breakup of the capsule in the gastric fluid, while elimination of the expanded system from the stomach would be ensured by the progressive dissolution of PVA.

\subsection{D printing of prototypes}

FDM was first used for the manufacturing of SMX GRDDS prototypes, and a trial-and-error approach was adopted. This consisted in introducing progressing changes into the virtual model (e.g. diameter, height and number of windings of the helix as well as dimensions of the relevant cross-section) based on the evaluation of the printed prototypes. Helices based on PVA05GLY-ALP were printed at 190 ${ }^{\circ} \mathrm{C}$ requiring the use of raft and supports to avoid collapse of the incomplete item during deposition of successive layers. The printing speed was kept relatively low $(23 \mathrm{~mm} / \mathrm{s})$ to avoid dragging of the latest layered material and reduce the vibrational stress undergone by the object during fabrication, which could cause its detachment from the build plate. The temporary shape was obtained by manual supercoiling of the helices, thus decreasing their diameter and reducing the distance between the different windings. Virtual models of the original shape were developed starting from the helix design already proposed for the intravesical device. Having the average dimensions of the open pyloric 
sphincter as a reference, helices having diameter of $15 \mathrm{~mm}$, height of $17 \mathrm{~mm}$, number of windings of 1.5 , thickness and height of the rectangular cross-section of 3 and $0.7 \mathrm{~mm}$, respectively, were finally selected as a result of the trial-and-error design activity. Helix-shaped samples with these characteristics were identified as a satisfactory balance between encumbrance of the original configuration and mechanical resistance to undergo manual programming of a supercoiled temporary shape for insertion into capsules. In this respect, size AA DB capsules were selected as their internal diameter (approximately $9.4 \mathrm{~mm}$ ) allowed the supercoiled helices to be housed. In Figure 4, virtual model and photographs of the selected 3D printed sample in the original and temporary shapes are reported. 4D printed systems had average weight of $571.70 \mathrm{mg}(\mathrm{cv}=7.31)$ and drug load of 9.82\% $(\mathrm{cv}=4.06)$.
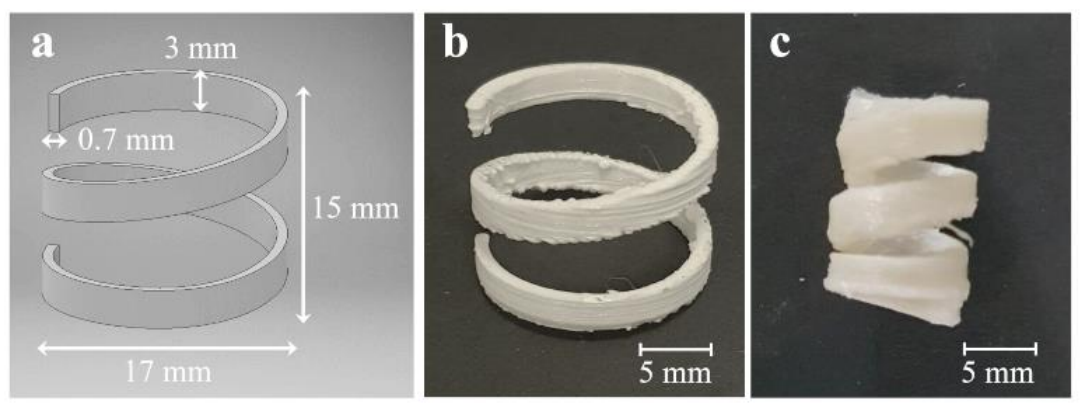

Figure 4: (a) virtual model with dimensional details and photographs of a cylindrical helix-shaped sample printed from PVA05GLY-ALP in the (b) original and (c) temporary shape.

\subsection{Performance of 4D printed prototypes}

Evaluation of shape recovery and release testing of the printed items in the final configuration intended for oral intake (i.e. helices in their temporary shape, inserted into capsules) were carried out in acidic fluid. Photographs of a system maintained at $37 \pm 0.5^{\circ} \mathrm{C}$ time under unstirred conditions are reported in Table 2 .

Immediately after immersion in $\mathrm{HCl} 0.1 \mathrm{~N}$, the capsule began to soften. Breakup occurred on the capsule side and was complete in $3 \mathrm{~min}$, in spite of a doubled wall thickness resulting from cap and 
body being overlapped. A major role of the pressure exerted by the helical device starting to expand was evident. In fact, analogous capsules filled with a blue powder tracer, tested under the same conditions, were shown to open in not less than $10 \mathrm{~min}$, as highlighted by solvent staining. Moreover, when the capsule was ruptured and a wider exposure of the sample to the acidic medium was possible, shape modification occurred faster. This was expected due to the combined effect of temperature and water on the shape memory of PVA already investigated (Melocchi A. et al., 2019). By visual inspection shape changes were no longer evident after $10 \mathrm{~min}$, period of time during which extensive recovery of the original shape was achieved. 


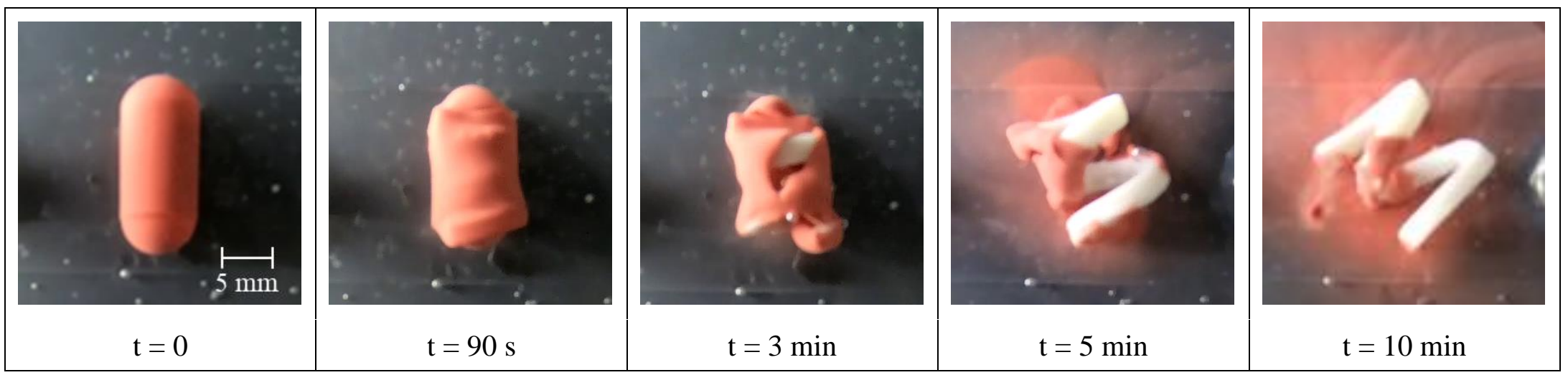

Table 2: photographs acquired during shape recovery of a cylindrical helix-shaped sample printed from PVA05GLY-ALP, inserted into a DB capsule after programming of the temporary supercoiled shape. 
For release testing, systems conveyed within capsules were immersed free into the vessels, regardless their expected tendency to float, because the presence of any constraints (e.g. sinkers) might have impacted on shape recovery. Floating was indeed observed though helical devices were released from the capsules in a few minutes while expanding and sinking. Drug release from the 4D printed systems was sustained over $2 \mathrm{~h}$ (Figure 5).

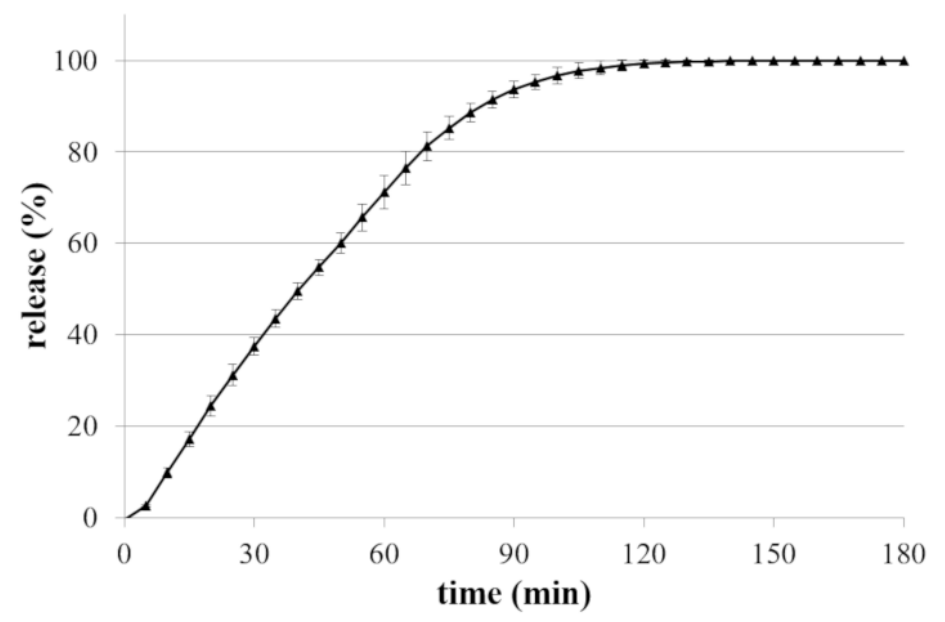

Figure 5: average release profile from cylindrical helix-shaped samples printed from PVA05GLYALP, inserted into DB capsules after programming of the temporary supercoiled shape.

\subsection{HME of prototypes}

Given the promising results obtained using FDM, which is currently proposed for customization of delivery systems, SMX GRDDSs having different design, mechanical characteristics, duration of retention and release kinetics were worth investigating (Zema et al., 2016). In this respect, a complete analysis of the thermo-mechanical behavior of PVA-based materials and devices through numerical simulations is ongoing. This approach would provide tools for the definition of the features of the system, reducing the number of experimental campaigns and the time as well as costs for testing. Starting from an empirical point of view, a simple approach was here adopted for the definition of further shapes of the device. The production was based on HME as this technology can overcome limits observed when printing by FDM high-viscosity materials (Melocchi et al., 2019). A higher 
molecular weight PVA, i.e. PVA18, was selected for the manufacturing of new prototypes, which would enable a better control of drug release rate.

The SMX GRDDS was conceived in different bulky original configurations, which could be achieved by post-processing of the extruded rod, i.e. by wrapping it around purposely-designed 3D printed templates of selected shapes. To simplify the experimental approach, all systems were obtained from a PVA18GLY-ALP rod of $1 \mathrm{~mm}$ in diameter. The method was inspired by that industrially used to produce corrugated breathing pipes via HME (Chan and Yi, 1989; Kolosov et al., 2012a, 2012b; Sidorov 2012; Sutton et al., 2010). The designed templates involved different rod lengths to yield the original shapes, resulting in differing amounts of drug contained in samples of diverse shape. In this way, dose modification may also be pursued. Virtual models of templates and of items shaped by their use, i.e. cylindrical and conical helix-, S- and atom-shaped samples, are reported in Figure 6, together with photographs of the prototypes actually obtained. The design of templates was the challenging step. Templates were conceived to allow easy manual wrapping of the material coming out of the extruder. Accordingly, the dimensions of the groove were adjusted to enable effortless fitting of the rods. Moreover, when possible, a stem was included in the template to serve as a handle, thus facilitating wrapping operations. Size attributes imposed for the system were at least 2 dimensions $>20 \mathrm{~mm}$ and deformation to a temporary shape suitable for being contained in capsules not larger than the $00 \mathrm{el}$ ones $($ i.e. body external diameter $=8.18 \mathrm{~mm}$ and length of the closed capsule $25.3 \mathrm{~mm}$ ). These were referred to as the standard size not to be exceeded for preserved patient acceptance and compliance (https://www.fda.gov/downloads/drugs/guidances/ucm377938.pdf; https://unitaid.org/assets/Lyndra-NC-September-2018.pdf). 

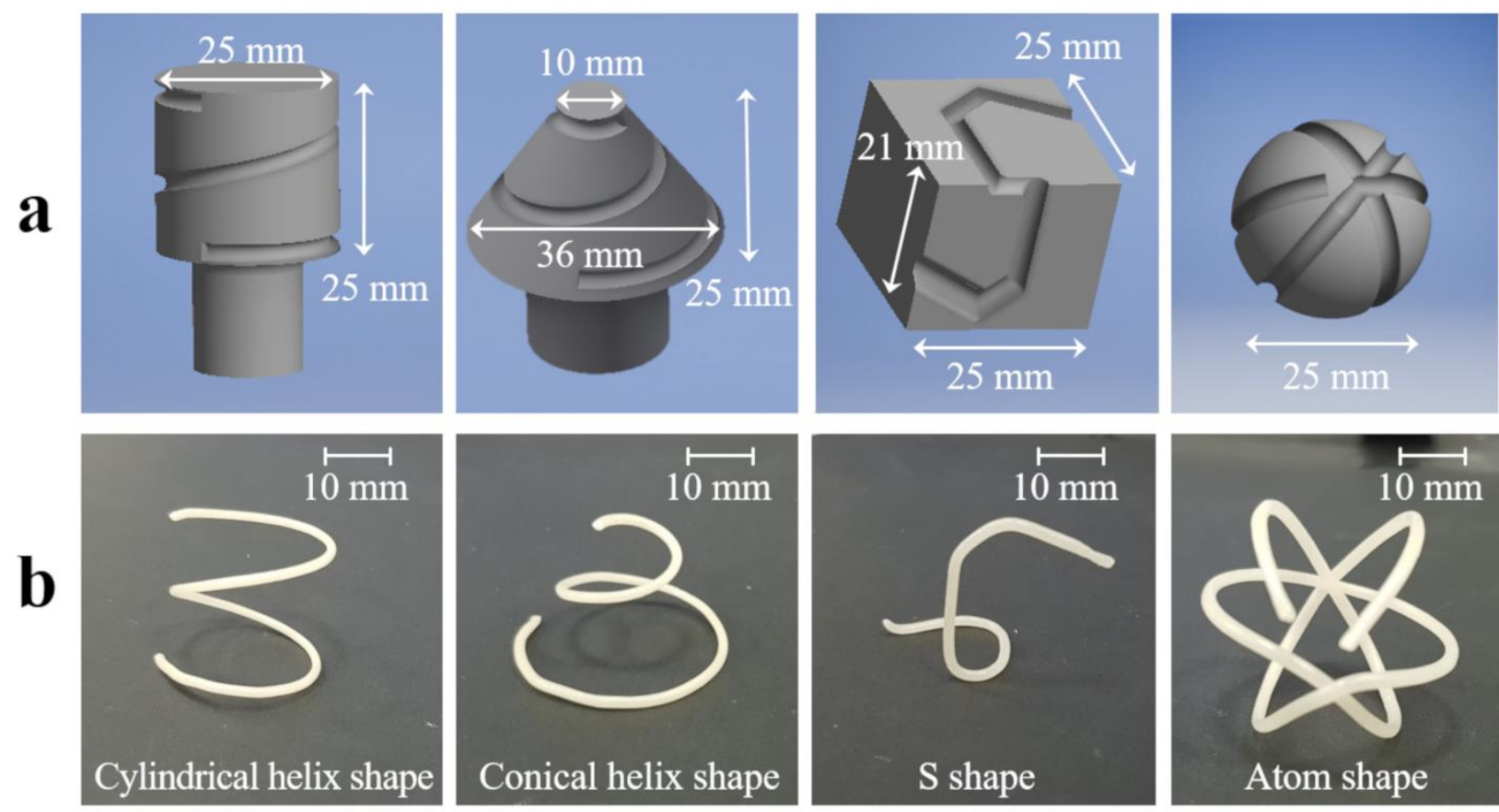

Figure 6: (a) virtual models of templates and (b) photographs of the samples obtained from cylindrical PVA18GLY-ALP rods of $1 \mathrm{~mm}$ in diameter.

In Table 3, the weight and ALP content data relevant to prototypes having different original configurations are reported. An amount of ALP consistent with the nominal one was measured from samples having different weights, thus confirming that no significant loss of drug occurred during HME. Moreover, weight variability of samples was reduced with respect to the printed items. This was partly attributed to the use of templates serving as a grid for wrapping and controlling the length of the rod.

Table 3: weight and drug content of samples having different original shapes.

\begin{tabular}{|l|l|l|}
\cline { 2 - 3 } \multicolumn{1}{c|}{} & $\begin{array}{l}\text { weight } \\
\text { mg }(\mathrm{cv})\end{array}$ & $\begin{array}{l}\text { ALP content } \\
\text { \% on nominal (cv) }\end{array}$ \\
\hline Cylindrical helix-shaped samples & $300.07(3.17)$ & $98.8(2.24)$ \\
\hline Conical helix-shaped samples & $298.62(4.09)$ & $99.3(1.93)$ \\
\hline S-shaped samples & $140.87(5.21)$ & $99.1(2.10)$ \\
\hline Atom-shaped samples & $401.87(4.23)$ & $99.6(1.89)$ \\
\hline
\end{tabular}


Templates to be employed for programming the temporary shape of the prototypes under development were also designed and 3D printed. Virtual models of the latter and photographs of samples deformed by their use are reported in Figure 7. With both conical and cylindrical helices, the same temporary shape, consisting in a supercoiled cylindrical helix, was used. On the other hand, Sshaped and atom-shaped samples were forced to take on paper clip and elliptical shapes, respectively. All these temporary shapes were demonstrated to fit into the 00el capsules (Figure 7c). Also in the programming step, the use of templates was proved useful to enhance the reproducibility of the process, making it less dependent on the operator.
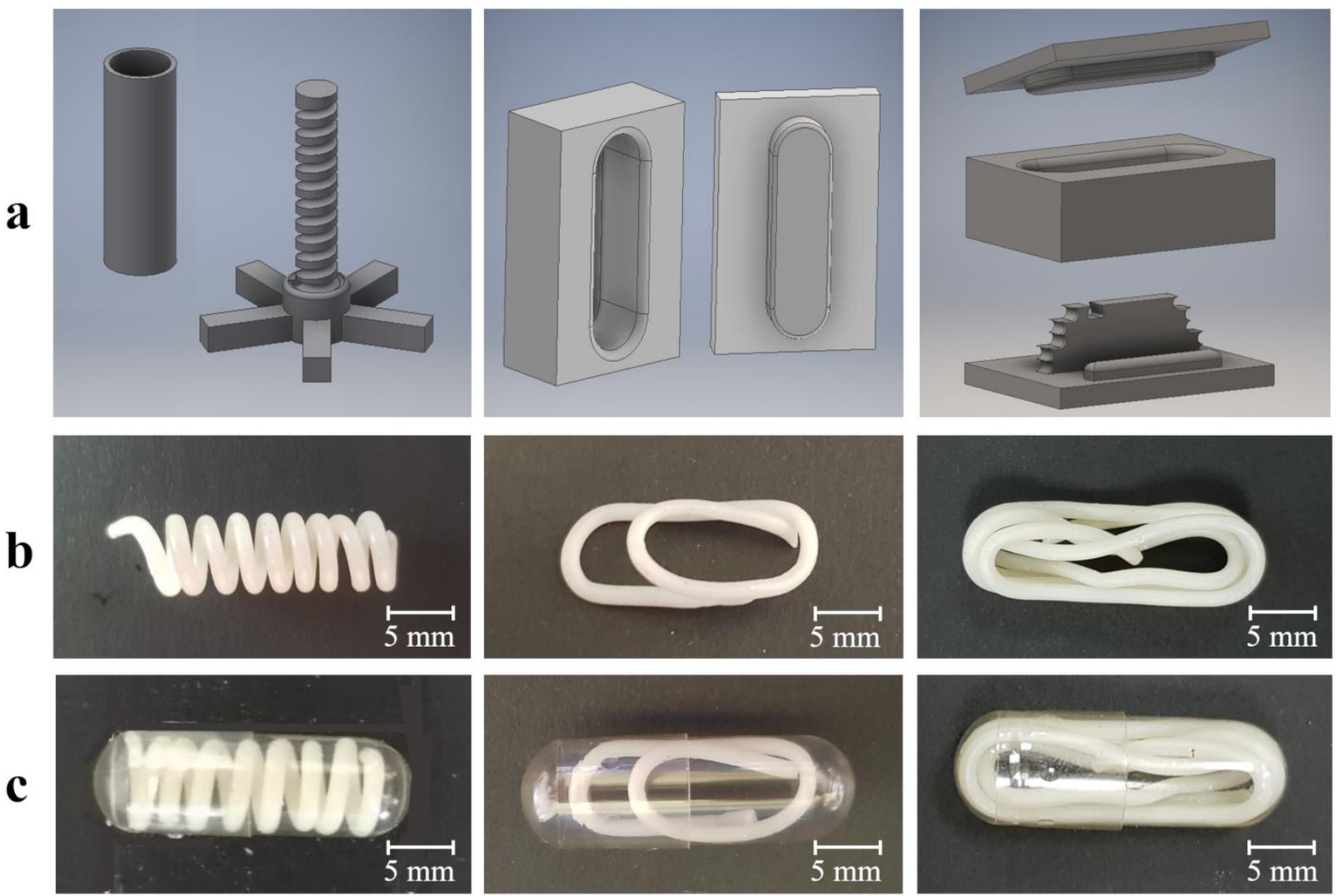

Figure 7: (a) virtual models for templates used to program the temporary shape and (b) photographs of the samples deformed by their use, obtained from PVA18GLY-ALP systems having different original shapes; (c) photographs of the deformed samples inserted into size 00el ConiSnap capsules. 
3.6 Performance of extruded prototypes

Cylindrical and conical helix-, S- and atom-shaped samples in their original shape, along with cylindrical helix-shaped ones coated with Eudragit ${ }^{\circledR}$ RS/ Eudragit ${ }^{\circledR}$ RL 1/1, were evaluated for release (Figure 8).

From all the uncoated devices, similar release patterns were obtained, pointing out negligible role of the length. Drug release was prolonged for approximately $2 \mathrm{~h}$. The release performance was not improved with respect to the printed PVA05-based specimens, despite the use of a higher molecular weight PVA. This was ascribed to the higher surface/volume ratio of the extruded systems (about 4 $\left.\mathrm{mm}^{-1}\right)$ as compared with the printed ones $\left(3.5 \mathrm{~mm}^{-1}\right)$. The selected die, resulting in relatively small size of the rod, was chosen in that it allowed a variety of temporary shapes to be easily obtained and compared.

The attempt to prolong the duration of release through application of an insoluble/permeable coating, such as resulting from the commonly used Eudragit ${ }^{\circledR}$ RS/ Eudragit ${ }^{\circledR}$ RL mixture, was proven effective, thus highlighting a possible formulation strategy worthy of further investigation.

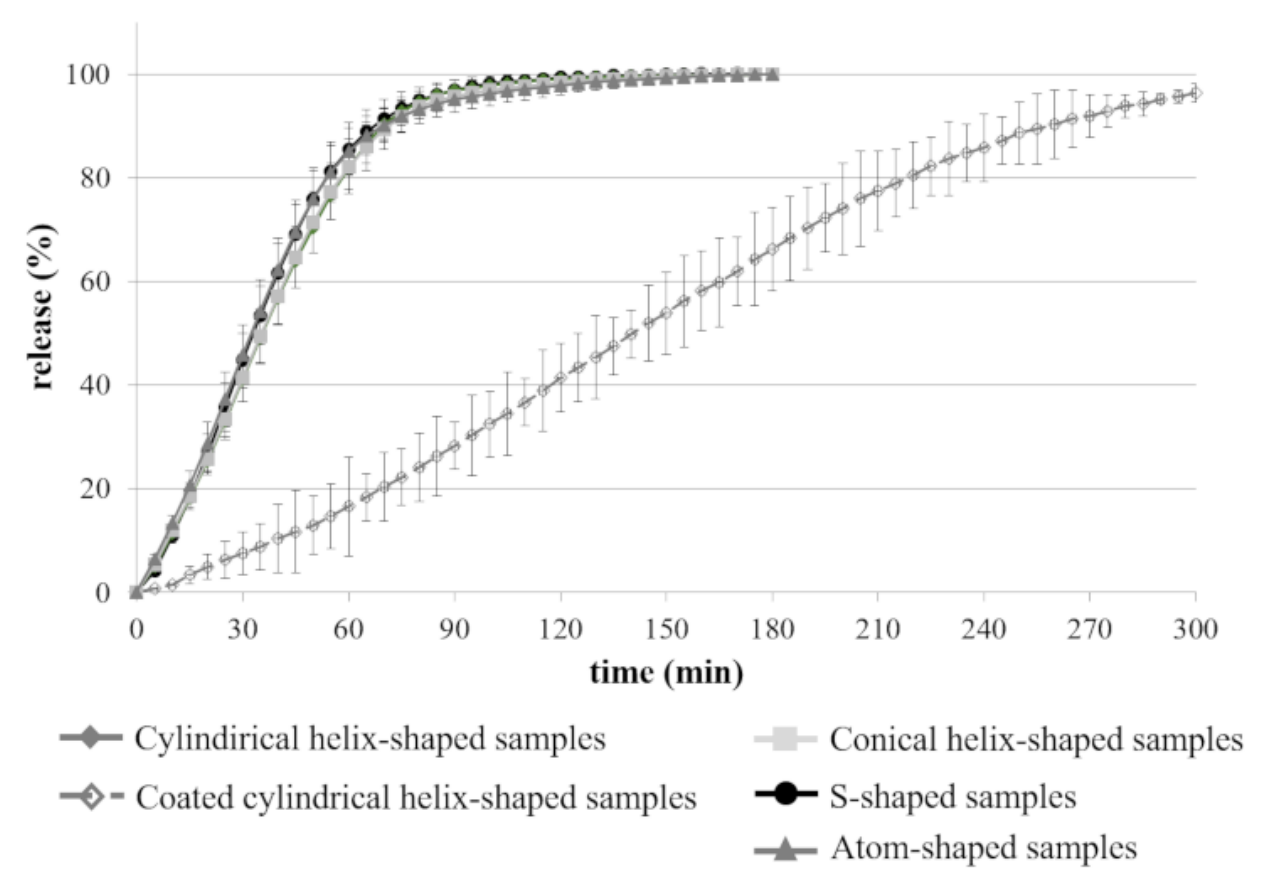

Figure 8: average release profiles from coated and uncoated extruded PVA18GLY-ALP samples having different original shapes. 
Further tests were performed with uncoated samples inserted into capsules. All the prototypes showed ability to recover the original shape except for the atom-shaped ones. This might be associated with the temporary shape imposed, characterized by many tight folds and thus involving longer lasting manual processing at the deformation temperature. As for the $4 \mathrm{D}$ printed prototypes, also the extruded systems showed the most marked changes in terms of shape recovery within the first minutes of testing. By way of example, photographs of a system having original conical helical shape, maintained at $37 \pm 0.5^{\circ} \mathrm{C}$ under unstirred conditions, are reported in Table 4 . Breakup of the capsule occurred after $45 \mathrm{~s}$. Also with extruded samples, the effect of the force exerted by the inner prototype while recovering its shape was evident. RI relevant to samples having conical and cylindrical helical shapes as well as $\mathrm{S}$ shape was also measured (Figure 9 and 10). In order to monitor increase in spatial encumbrance of the systems over time, specific RIs were calculated for each shape. In all cases, exceeding dimensions of $13 \mathrm{~mm}$ was used as the criterion for acceptable shape recovery.

When dealing with conical and cylindrical helices, recovery of the initial diameter was considered the crucial step. In fact, the length of such items in the supercoiled temporary shape was already $>20$ mm. A diameter greater than or equal to $13 \mathrm{~mm}$, corresponding to a RIø of $41 \%$ and $23 \%$ for cylindrical and conical helices, respectively, was achieved in less than 2 min (Figure 9a and 9b). Moreover, the samples gained approximately $90 \%$ and $60 \%$ of their original diameter within 5 min of testing. The time for reaching the threshold dimension was relatively short, which could be attributed to the combined effect of temperature and fast water uptake of the systems. This was considered potentially suitable for addressing a major safety issue of expandable GRDDSs, connected with the time needed to achieve the bulky retentive configuration. Indeed, late expansion might result in small intestine location of the system with possible clogging of the canal, and also loss of the absorption window with consequent reduction of bioavailability.

To define the overall spatial encumbrance of the helices, RIø/h was also evaluated. Setting the diameter-to-height ratio of samples in their original shape equal to 100 , cylindrical helices exhibited 
the ability to reach $77 \%$ of $\mathrm{RI} \varnothing / \mathrm{h}$ in $5 \mathrm{~min}$, while items with conical helical shape recovered about $60 \%$ in the same time frame.

Because recovery of S shape involved the opening of the temporary paper-clip configuration, it was evaluated by measuring three angles associated with xy, zx and yz planes, i.e. $\alpha_{\mathrm{xy}}, \alpha_{\mathrm{xz}}$, and $\alpha_{\mathrm{yz}}$ (Figure 2c and Figure 10). For these systems, simultaneous widening of two angles would be sufficient to achieve size compatible with gastric retention. $43^{\circ}, 33^{\circ}$ and $32^{\circ}$ were calculated to be the threshold limits for $\alpha_{x y}, \alpha_{x z}$, and $\alpha_{y z}$, respectively. Such values were always reached within 5 min of testing and kept increasing. Evident changes were no longer recorded after $15 \mathrm{~min}$. In this time frame, $\alpha_{\mathrm{xy}}$ and $\alpha_{y z}$ achieved approximately $70 \%$ of recovery, while $\alpha_{x z}$ reached almost $90 \%$. This could be associated with the possibility of the system to freely move in the xz plane, while the opening of $\alpha_{\mathrm{xy}}$ and $\alpha_{\mathrm{yz}}$ might have been hindered by the sliding friction on the bottom surface of the crystallization vessel. Evaluation of the shape memory performance was also carried out after storage of the prototypecontaining capsules at ambient conditions for at least 1 month and no major changes were highlighted. Release profiles of prototypes in their temporary shape, tested either free or inserted into capsules, were shown to be analogous to that of samples in their original shape, confirming the robustness of the SMX GRDDS under development.

As regards cylindrical helix-shaped samples provided with the Eudragit ${ }^{\circledR}$ RS/ Eudragit ${ }^{\circledR}$ RL coating, promising results were preliminary obtained demonstrating their capability of being programmed in the temporary supercoiled configuration, recovering the original shape upon contact with aqueous fluid at body temperature and slowly releasing the drug tracer over $6 \mathrm{~h}$. 


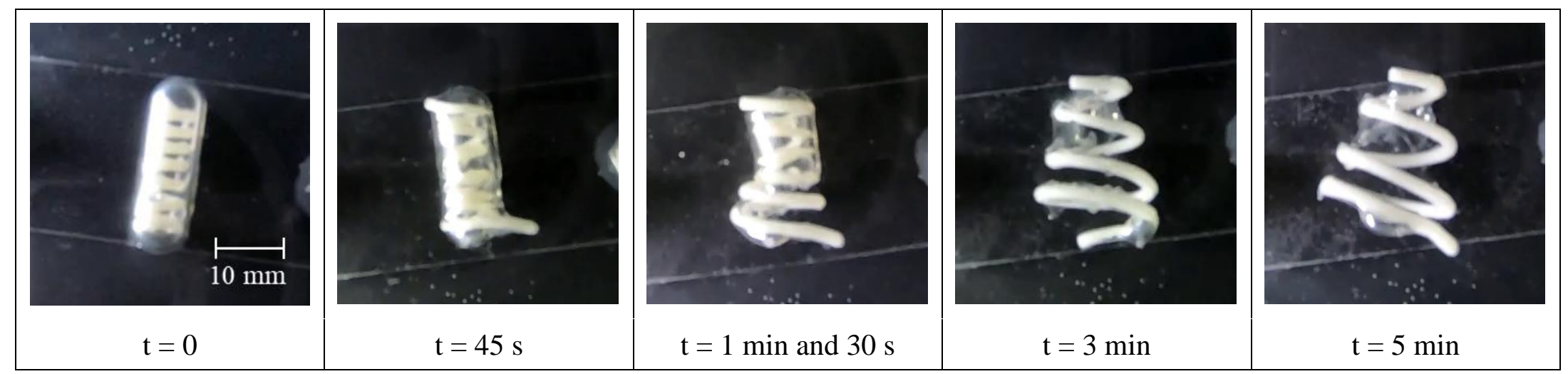

Table 4: photographs acquired during shape recovery of a conical helix-shaped sample extruded from PVA05GLY-ALP, inserted into size 00el Coni-Snap capsule after programming of the temporary supercoiled shape. 
a

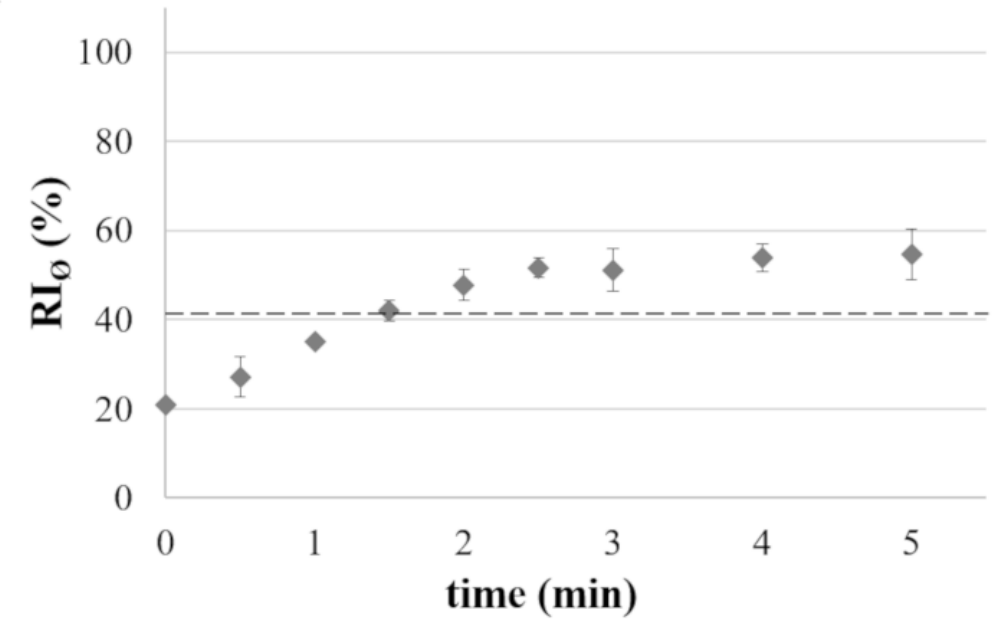

b

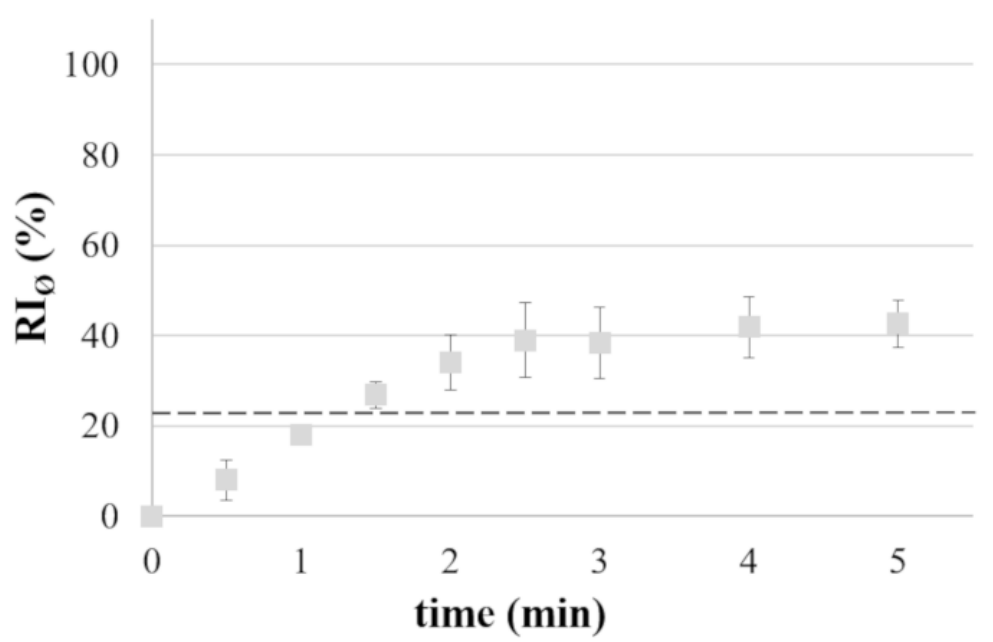

Figure 9: RIø versus time curves relevant to samples having original (a) cylindrical and (b) conical helical shapes. The dashed lines represent threshold RIø. 
a

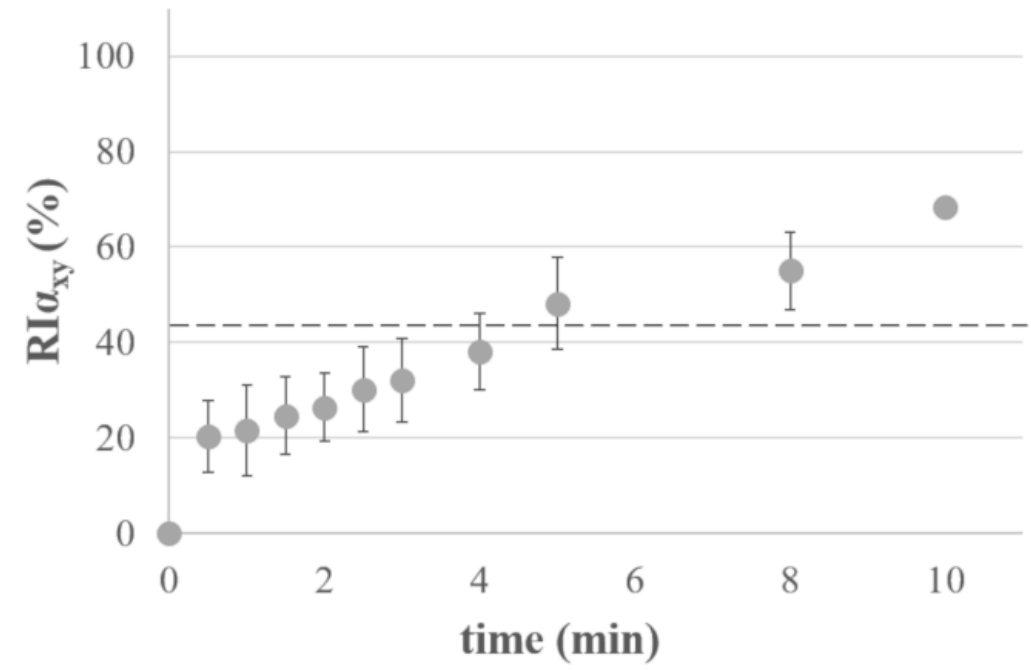

b

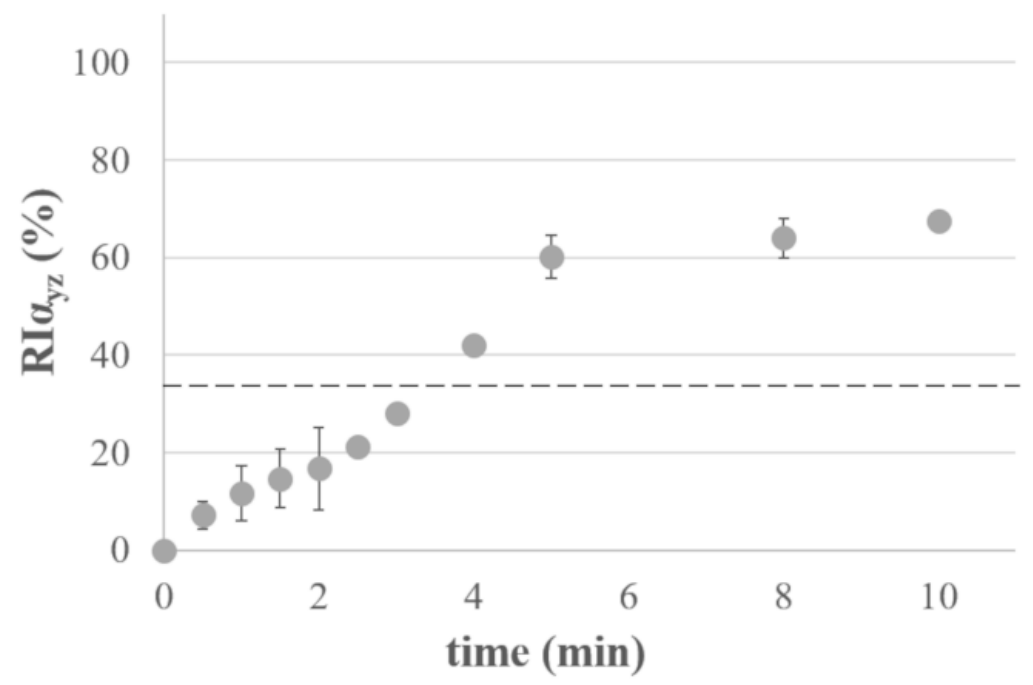

$\mathbf{C}$

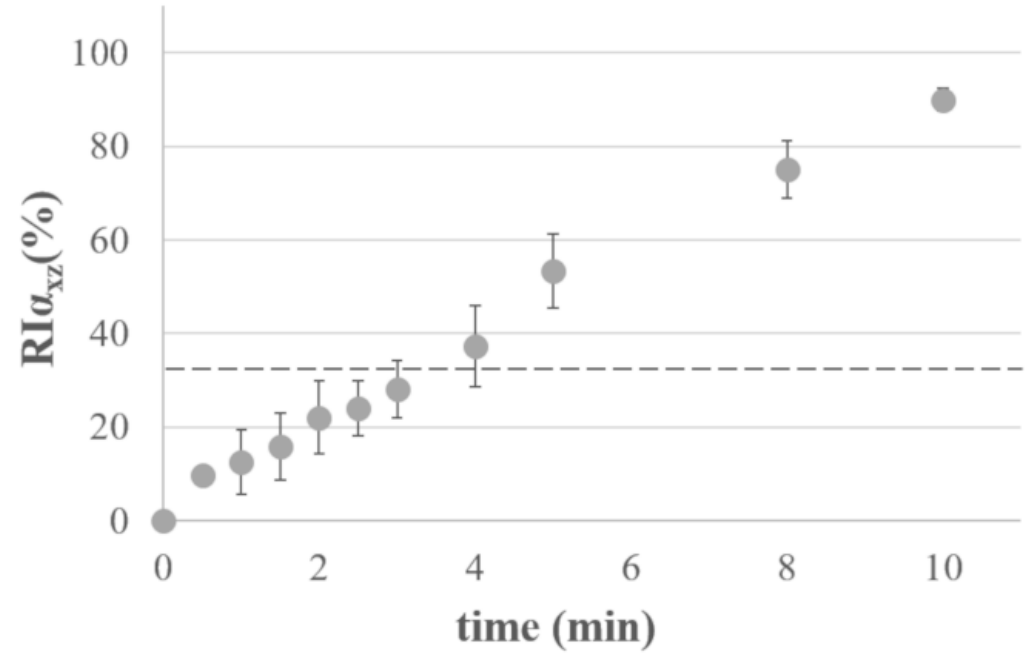

Figure 10: $\mathrm{RI}_{\alpha(\mathrm{x}, \mathrm{y}, \mathrm{z})}$ versus time curves relevant to samples having original $\mathrm{S}$ shape. The dashed lines represent threshold $\mathrm{RI}_{\alpha(\mathrm{x}, \mathrm{y}, \mathrm{z}) \text {. }}$ 


\section{Conclusions}

In the present work, a novel expandable GRDDS was described. Gastric retention is of great interest in the case of drugs that are absorbed to a greater extent in the upper gastrointestinal tract or indicated for the therapy of widespread local diseases. Indeed, they would increase patient compliance because of reduced frequency of administration and enhance the therapy efficacy. The strategy here pursued was based on the use of pharmaceutical-grade PVA, which was already proved to be endowed with shape memory ability. This would allow the system to spontaneously shift from a temporary shape programmed by deformation, suitable for oral administration, to an expanded original one enabling gastric retention due to proper spatial encumbrance. The proposed device could thus be considered a shape-memory expandable GRDDS (SMX GRDDS). Because the relevant expansion mechanism is based on the combination of body temperature and contact with a minimum volume of fluids, the system may only poorly be susceptible to physiological variables of the gastric environment. Prototypes having different original shapes were successfully manufactured either directly by 4D printing or by manual processing of extruded rods. A quantitative method was set up to evaluate shape modifications undergone by extruded samples over time in unstirred acidic environment at $37 \pm 0.5$ ${ }^{\circ} \mathrm{C}$. The temporary shape enabled, in all cases, insertion into commercial gelatin capsules of widely used sizes. A satisfactory extent of recovery of the original cylindrical and conical helix as well as $\mathrm{S}$ shapes was reached in a few minutes with respect to a previously set threshold value. Shape changes imposed through heating and mechanical deformation were demonstrated not to impact on the release performance of prototypes. However, the timescale of the release process was found to be an issue, in view of the longer-lasting performance that is known to be required for GRDDSs. In this respect, the application of a diffusive polymeric film onto cylindrical extruded helices was demonstrated a suitable formulation approach to prolong release over $6 \mathrm{~h}$.

In future development studies, further improvement of the duration of release could be pursued primarily entailing selection of different release-controlling coating formulations, of PVAs with higher molecular weights or else of different shape memory polymers. Moreover, modification in the 
overall surface/volume ratio of the device and changes in the length of extruded rods to increase the drug load will be taken into account. In this respect, the versatility that the manufacturing approach would provide could be advantageous. An in-depth evaluation of the mechanical behavior of the system and the contribution of temperature and amount of water on its expansion will also be performed.

\section{References}

Altreuter D. H., Kirtane A. R., Grant T., Kruger C., Traverso G., Bellinger A. M., 2018, Changing the pill: developments toward the promise of an ultra-long-acting gastroretentive dosage form, Expert Opin. Drug Deliv., 15: 1189-1198.

Bardonnet P. L., Faivre V., Pugh W. J., Piffaretti J. C., Falson F., 2006, Gastroretentive dosage forms: overview and special case of Helicobacter pylori, J. Control Release, 111: 1-18.

Beck R.C.R., Chaves P.S., Goyanes A., Vukosavljevic B., Buanz A., Windbergs M., Basit A.W., Gaisford S., 2017, 3D printed tablets loaded with polymeric nanocapsules: An innovative approach to produce customized drug delivery systems, Int. J. Pharm., 528: 268-279.

Bellinger A. M., Jafari M., Grant T. M., Zhang S., Slater H. C., Wenger E. A., Mo S., Lee Y.- A. L., Mazdiyasni H., Kogan L., Barman R., Cleveland C., Booth L., Bensel T., Minahan D., Hurowitz H. M., Tai T., Daily J., Nikolic B., Wood L., Eckhoff P. A., Langer R., Traverso G., 2016, Oral, ultralong-lasting drug delivery: application toward malaria elimination goals, Sci. Transl Med., 8: 1-12.

Chan H., Yi B., 1989, Pipe extrusion die with a cooled and vacuumed additional mandrel, Patent number: 4,808,098

Chen J., Blevins W. E., Park H., Park K., 2000, Gastric retention properties of superporous hydrogel composites, J. Control Release, 64: 39-51. 
Ding Z., Yuan C., Peng X., Wang T., Qi H.J., Dunn M.L., 2017, Direct 4D printing via active composite materials, Sciences Adv., 3: e1602890-e1602896.

Gao B., Yang Q., Zhao X., Jin G., Ma Y., Xu F., 2016, 4D bioprinting for biomedical applications, Trends Biotechnol. 34: 746-756.

Genina N., Boetker J.P., Colombo S., Harmankaya N., Rantanen J., Bohr A., 2017, Anti-tuberculosis drug combination for controlled oral delivery using 3D printed compartmental dosage forms: From drug product design to in vivo testing, J. Control. Release, 268: 40-48.

Goyanes A., Kobayashi M., Martínez-Pacheco R., Gaisford S., Basit A.W., 2016, Fused-filament 3D printing of drug products: Microstructure analysis and drug release characteristics of PVA-based caplets, Int. J. Pharm., 514:1 291-295.

Gupta R., Tripathi P., Bhardwaj P., Maho A., 2018, Recent advances in gastro retentive drug delivery systems and its application on treatment of H. Pylori infections, J. Anal. Pharm. Res., 7: 404-410.

https://www.drugbank.ca/drugs/DB00437, last access on July 15, 2019.

https://www.fda.gov/downloads/drugs/guidances/ucm377938.pdf, last access on July 15, 2019.

https://unitaid.org/assets/Lyndra-NC-September-2018.pdf, last access on July 15, 2019.

Huang W. M., Ding Z., Wang C. C., Wei J., Zhao Y., Purnawali H., 2010, Shape memory materials, Mater. Today 13: 54-61.

Jaeger H., Russmann D., Rasper J., Blome J., 1982, Comparative study of the bioavailability and the pharmacodynamic effect of five allopurinol preparations (author's translation, Article in German), Arzneimittelforschung, 32: 438-443.

Kirtane A. R., Abouzid O., Minahan D., Bensel T., Hill A. L., Selinger C., Bershteyn A., Craig M., Mo S. S., Mazdiyasni H., Cleveland C., Rogner J., Lee Y.- A. L., Booth L., Javid F., Wu S. J., Grant 
T., Bellinger A.M., Nikolic B., Hayward A., Wood L., Eckhoff P.A., Nowak M.A., Langer R., Traverso G., 2018, Development of an oral once-weekly drug delivery system for HIV antiretroviral therapy, Nat. Commun., Article Number 2294, 9: 1-12.

Klausner E.A., Lavy E., Borta M., Cserepes E., Friedman M., Hoffman A., 2003a, Novel gastroretentive dosage forms: evaluation of gastroretentivity and its effect on levodopa absorption in humans, Pharm. Res., 20: 1466-1473.

Klausner E. A., Lavy E., Friedman M., Hoffman A., 2003b, Expandable gastroretentive dosage forms, J. Control. Release, 90: 143-162.

Kollamaram G., Croker D.M., Walker G.M., Goyanes A., Basit A.W., Gaisford S., 2018, Low temperature fused deposition modeling (FDM) 3D printing of thermolabile drugs, Int. J. Pharm. 545: 144-152.

Kolosov A. E., Sakharov A. S., Sidorov D. E., Sivetskii V.I., 2012b, Aspects of profile shaping of corrugated tubular components. Part 3. Extrusion shaping of tubular polymeric blanks for manufacture of corrugated pipes, Chem. Pet. Eng., 48: 199-206.

Kumar M., Kaushik D., 2018, An overview on various approaches and recent patents on gastroretentive drug delivery systems, Recent Pat. Drug Deliv. Formul., 12: 84-92.

Lee A.Y., An J., Chua C.K., 2017, Two-way 4D printing: a review on the reversibility of 3D-printed shape memory materials, Eng. 3: 63-674.

Liu J., Pang Y., Zhang S., Cleveland C., Yin X., Booth L., Lin J., Lucy Lee Y. - A., Mazdiyasni H., Saxton S., Kirtane A.R., Erlach T.V., Rogner J., Langer R., Traverso G., 2017, Triggerable tough hydrogels for gastric resident dosage forms, Nat. Commun., Article Number 124, 8: 1-10. 
Liu X., Steiger C., Lin S., Parada G.A., Liu J., Chan H.F., Yuk H., Phan N.V., Collins J., Tamang S., Traverso G., Zhao X., 2019, Ingestible hydrogel device, Nat. Commun., Article Number 493, 10: 1 10.

Lopes C. M., Bettencourt C., Rossi A., Buttini F., Barata P., 2016, Overview on gastroretentive drug delivery systems for improving drug bioavailability, Int. J. Pharm., 510: 144-158.

Loreti G., Maroni A., Del Curto M. D., Melocchi A., Gazzaniga A., Zema L., 2014, Evaluation of hot-melt extrusion technique in the preparation of HPC matrices for prolonged release, Eur. J. Pharm. Sci., 52: 77-85.

Maniruzzamann M. (Ed.), 3D and 4D printing in biomedical applications: process engineering and additive manufacturing, Weinheim: Wiley VCH; 2018.

Maroni A., Melocchi A., Parietti F., Foppoli A., Zema L., Gazzaniga A., 2017, 3D printed multicompartment capsular devices for two-pulse oral drug delivery, J. Control. Release, 268: 10-18.

Matijašić G., Gretić M., Vinčić J., Poropat A., Cuculić L., Rahelić T., 2019, Design and 3D printing of multi-compartmental PVA capsules for drug delivery, J Drug Deliv. Sci. Technol., 52: 677-686.

Melocchi A., Parietti F., Loreti G., Maroni A., Gazzaniga A., Zema L., 2015a, 3D printing by fused deposition modeling (FDM) of a swellable/erodible capsular device for oral pulsatile release of drugs, J, Drug Deliv. Sci. Technol. 30 Part B: 360-367.

Melocchi A., Loreti G., Del Curto M.D., Maroni A., Gazzaniga A., Zema L., 2015b, Evaluation of hot-melt extrusion and injection molding for continuous manufacturing of immediate-release tablets, J. Pharm. Sci., 104: 1971-1980.

Melocchi A., Parietti F., Maroni A., Foppoli A., Gazzaniga A., Zema L., 2016, Hot-melt extruded filaments based on pharma-grade polymers for 3D printing by fused deposition modeling, Int. J. Pharm., 509: 255-263. 
Melocchi A., Parietti F., Maccagnan S., Ortenzi M.A., Antenucci S., Briatico-Vangosa F., Maroni A., Gazzaniga A., Zema L., 2018, Industrial development of a 3D-printed nutraceutical delivery platform in the form of a multicompartment HPC capsule, AAPS PharmSciTech., 19: 3343-3354.

Melocchi A., Inverardi N., Uboldi M., Baldi F., Maroni A., Pandini S., Briatico-Vangosa F., Zema L., Gazzaniga A., 2019, Retentive device for intravesical drug delivery based on water-induced shape memory response of poly(vinyl alcohol): design concept and 4D printing feasibility, Int. J. Pharm., 559: 299-311.

Mohsin M., Hossin A, Haik Y., 2011, Thermal and mechanical properties of poly(vinyl alcohol) plasticized with glycerol, J. Appl. Polym. Sci. 122: 3102-3109.

Omidian H., Rocca J. G., Park K., 2005, Advances in superporous hydrogels, J. Control Release, 102: 3-12.

Rouge N., Buri P., Doelker E., 1996, Drug absorption sites in the gastrointestinal tract and dosage forms for site-specific delivery, Int. J. Pharm., 136: 117-139.

Sharma O. P., Shah M. V., Parikh D. C., Mehta T. A., 2015, Formulation optimization of gastroretentive drug delivery system for allopurinol using experimental design, Expert Opin. Drug Deliv., 12: 13-524.

Sidorov D. E., Sivetskii V.I., Kolosov A. E., Sakharov A. S., 2012, Shaping of corrugation profiles during production of corrugated tubular articles, Chem. Pet. Eng., 48: 384-390.

Sutton G.S., Hamilton; Kelley D. J., Kolbet R.A., 2010, Systems and methods for making multi-wall corrugated pipe, Patent number: US 2010/022430.6 A1

Verma S., Nagpal K., Singh S. K., Mishra D. N., 2014, Unfolding type gastroretentive film of Cinnarizine based on ethyl cellulose and hydroxypropylmethyl cellulose, Int. J. Biol. Macromol., 64: 347-352. 
Zarek M., Layani M., Cooperstein I., Sachyani E., Cohn D., Magdassi S., 2015, 3D printing of shape memory polymers for flexible electronic devices, Adv. Mater., 28: 4449-4454.

Zarek M., Mansour N., Shapira S., Cohn D., 2017, 4D Printing of shape memory-based personalized endoluminal medical devices, Macromol. Rapid Commun., 38: 1600628.

Zema L., Melocchi A., Maroni A., Gazzaniga A., 2016, 3D printing of medicinal products and the challenge of personalized medicine, J. Pharm. Sci., 106: 1697-1705. 